\title{
System Dynamics Model of the Kinetics of Biogas Production from Vegetal Matter
}

\author{
Abiodun Suleiman Momodu ${ }^{1, *}$, Tofunmi Dorcas Adepoju² \\ ${ }^{1}$ Centre for Energy Research and Development, Obafemi Awolowo University, Ile-Ife, Nigeria \\ ${ }^{2}$ Youth National Service, Energy Commission of Nigeria, Garki, Abuja, Nigeria \\ Email address: \\ abiodunmomodu8@gmail.com(A. S. Momodu), adepojutofunmi001@gmail.com(T. D. Adepoju) \\ ${ }^{*}$ Corresponding author
}

\section{To cite this article:}

Abiodun Suleiman Momodu, Tofunmi Dorcas Adepoju. System Dynamics Model of the Kinetics of Biogas Production from Vegetal Matter. International Journal of Energy and Power Engineering. Vol. 9, No. 2, 2020, pp. 22-28. doi: 10.11648/j.ijepe.20200902.11

Received: March 17, 2020; Accepted: March 27, 2020; Published: April 29, 2020

\begin{abstract}
The use of renewable energy sources including biomass for energy generation, to achieve diversification in energy production, has been found to be sustainable economically, financially and environmentally. Various energy production technologies exist by which biomass can be converted for energy generation. Such technologies include anaerobic digestion, gasification, thermal depolymerization, pyrolysis, fermentation, anaerobic digestion, amongst others. The focus of this study is on the use of anaerobic digestion technology. Anaerobic digestion is recognized as one of the best options for treating biomass as it helps to avoid $\mathrm{CO}_{2}$ emissions and run off of biomass. It is a natural process in which bacteria convert organic materials into biogas and fertilizer production in an environmentally friendly way. Anaerobic digestion is a series of sequential process including hydrolysis, acidogenesis, acetogenesis and methanogenesis. Different models have been applied to capture the characteristics of the anaerobic digestion process such as first-order model, Gompertz model and logistic model. However, Gompertz model is considered as the best model in describing the growth of animals and plants as well as the volume of bacteria. It is also used to describe the cumulative biogas production curve in batch digestion assuming that substrate levels limit growth in a logarithmic relationship. This study developed a System Dynamics model (SDM) for predicting biogas production (BP) in an anaerobic condition, based on Gompertz-Laird model. The objective is to describe the process of a System Dynamic (SD) model of two stage kinetics of BP. Primary data used were obtained from a laboratory experiment of BP using vegetal wastes, while secondary data were obtained from literature on studies using similar substrates. The Causal loop diagram generated, describes the anaerobic digestion (AD) process usually undergone by a substrate, while the Stock Flow diagram depicts the building blocks of the dynamic behavior of the same process. The developed SD model consists of two-level variables which depict the equations driving the $\mathrm{AD}$ process represented as hydrolysis-acidogenesis and acetogenesis-methanogenesis. The model results showed a significant lag phase between methanogenesis and fermentation stage, which was found to be linked to the inoculum-substrate ratio. The study conclusion includes: inoculum to substrate ratio affects BP; inconsistency of the experimental data caused by inhibition explains the variation observed between the empirical and simulated results.
\end{abstract}

Keywords: System Dynamics, Kinetics, Biogas, Vegetal Matter

\section{Introduction}

Energy provision is essential for economic growth and development $[1,2]$, such that the per capita consumption level of energy of countries is correlated with their living standards $[3,4]$. For example, a country like Nigeria that is oil-rich is still mostly dependent on petroleum products to drive its economy. It has very low per capita energy consumption. This is detrimental in economic and environmental terms due to poor living standards and the generation of inimical climate change effects. To this end, it becomes imperative to diversify energy production sources to meet the ever-growing energy demand, particularly in rural and remote areas of the country. These energy productions could be from primary or secondary sources. Primary energy sources are mainly classified as renewable or non- renewable based on whether they draw on a depleting energy resource 
or not [5]. Secondary energy, on the other hand, refers to any energy that is obtained from a primary energy source employing a transformation or conversion process. Examples include oil products (petrol or gasoline, diesel, liquefied petroleum product, etc.) or electricity, as these require refining or electric generators to produce them.

Nonrenewable-based energy sources such as fossil fuels generate high carbon emissions, whereas hydro, wind, solar, wave, and biomass energy sources generally treated as renewable have low or no emissions. The use of renewable energy sources, including biomass for energy generation, has been found to be sustainable economically, financially, and environmentally [6].

Various energy production technologies exist by which biomass can be converted for energy generation. Such technologies include anaerobic digestion, gasification, thermal depolymerization, pyrolysis, thermal depolymerization, pyrolysis, fermentation, and anaerobic digestion, amongst others [7]. The focus of this study is on the use of anaerobic digestion technology. Anaerobic digestion is recognized as one of the best options for treating biomass, as it helps to avoid $\mathrm{CO}_{2}$ emissions and run off of biomass [8]. It is a natural process in which bacteria convert organic materials into biogas and fertilizer production in an environmentally friendly way. Anaerobic digestion is a series of sequential processes, including hydrolysis, acidogenesis, acetogenesis, and methanogenesis.

The study, which is a preliminary step, aims to develop a System Dynamics model (SDM) for predicting biogas production under anaerobic conditions. The primary objective therefore, is to describe the process of developing a System Dynamics (SD) model of two-stage kinetics of biogas production. This objective is with the ultimate aim of generating a predictive SD model for biogas production potential from any digester operating under anaerobic conditions.

Summarily the paper is structured as follows: introduction, literature review, methodology, result and discussion, and then conclusions.

\section{Literature Review}

Few studies have been reported on the dynamic behavior of biogas production systems in modeling and simulation. This has been attributed to the complexities and complications involved in biogas production systems [9-11]. In the context of this study, few of such studies have been reviewed with regard to the mechanisms behind the anaerobic digestion process. For instance, [11] reported on the System Dynamics study of biogas production. They posit that SD presents the simplest and quickest route to the understanding of dynamic systems such as biogas production systems through models. This is because SD is capable of incorporating inherent nonlinearity and time lag of the system [12, 11]. Similarly, [13] stated that kinetic models are useful tools to optimize the anaerobic digestion process in system dynamics. It has also been reported that kinetics pertaining to biomethanation help in understanding the mechanisms of the anaerobic digestion process [14, 15]. Researchers have deeply studied the influence of physical and chemical conditions on the anaerobic digestion of substrates [16-18]. These influences have been modeled using different types of kinetic models, including kinetics of substrate degradation, growth kinetics, and kinetics of biogas production [16-18]. Kythreotou et al. and Nopharatana et al. also reported that the kinetic model of biogas production was found to be the most important [18-19].

Different models have been applied to capture the characteristics of the anaerobic digestion process, such as the first-order model, Gompertz model, and logistic model [20, 21]. However, from [20], the Gompertz model is considered the best model. The Gompertz model describes the growth of animals and plants as well as the volume of bacteria. It also describes the cumulative biogas production curve in batch digestion, assuming that substrate levels limit growth in a logarithmic relationship [20, 22]. There are two main types of Gompertz models, varying depending on the number of parameters in them. These include the four-parameter Gompertz, Zwietering modification, Zweifel and Lasker re-parameterization, Gompertz-Laird, and Unified-Gompertz [23].

\subsection{Theoretical Concept}

Gompertz-Laird is one of the more commonly used because it presents a better adjustment for models [24]. The Gompertz-Laird model is given in equation (1):

$$
G_{t}=A \times \operatorname{Exp}\left\{-\exp \left[\frac{\mu_{\mathrm{m}} \times \operatorname{Exp}(1)}{A}(\lambda-\mathrm{t})+1\right]\right\}
$$

where $G_{t}$ is the cumulative biogas yield at digestion time $t$ ( $\mathrm{Nml} / \mathrm{g}-\mathrm{VS}), \mathrm{A}$ is the biogas yield potential of the substrates $(\mathrm{Nml} / \mathrm{g}-\mathrm{VS}), \mu \mathrm{m}$ is the maximum biogas production rate $(\mathrm{Nml} / \mathrm{g}-\mathrm{VS}), \lambda$ is the lag phase period or minimum time to produce biogas (day), and $\mathrm{t}$ is the digestion time (day).

Although, in the Gompertz model, the lag phase period $(\lambda)$ parameter was proved as a mathematical constant and not to be a biological one. This also implies that when time, $\mathrm{t}=0$, the Gompertz model will always fail to describe the starting time [11]. Therefore, to overcome this limitation, a new biogas production kinetic model was proposed. This new proposed model introduces meaningful parameters for biogas yield potential of substrates $\mathrm{A}, \mu \mathrm{m}$, and $\mathrm{t}_{0}$ as the time when the gas production rate reaches the maximum value for simulation of biogas production.

This new proposed model forms the basis for which the SD model in this study was developed as described next.

\subsection{SD Model Formulation}

Having established the theoretical concept, it is important to give a brief description of SD model formulation. This involves the following processes: problem definition, identification of key variables that lead to the causal diagram, development of the model involving reference mode development, and stock-flow diagram [25]. For this study, this problem definition involves a description of the kinetics of biogas production. The developed model seeks to express the kinetics of biogas production based on the SD approach. The two steps for SD 
model development are basically generating the causal and stock-flow diagrams of the system being examined.

\section{Methodology}

This describes the process of developing a System Dynamic (SD) model of two-stage kinetics of biogas production. Primary and secondary data were used to validate and stimulate the developed model. The primary data were obtained from a laboratory experiment on biogas production using vegetal wastes, while the secondary data were obtained from the literature of the same kind of substrate.

\subsection{Causal Loop Diagramming (CLD)}

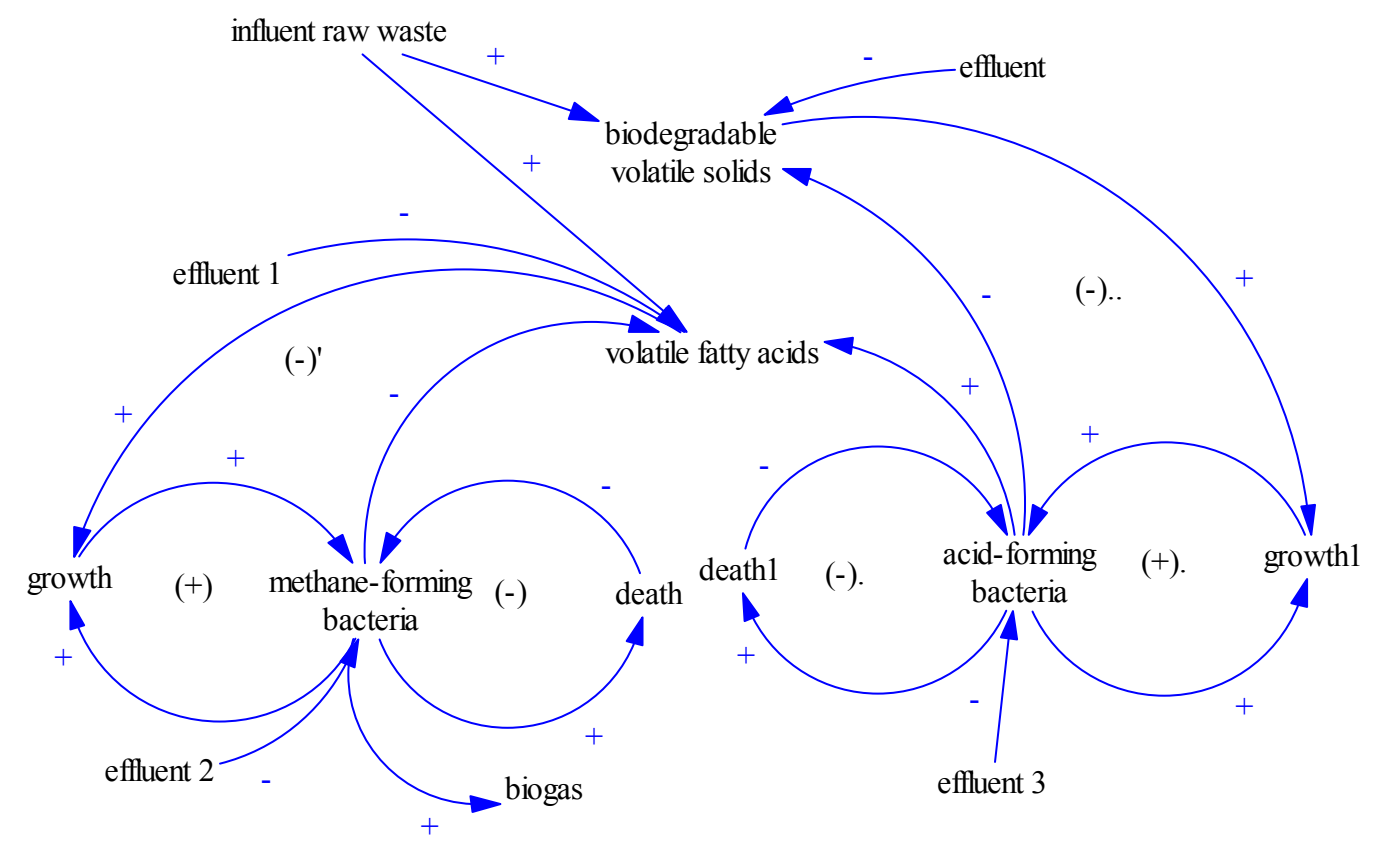

Figure 1. Causal diagram of experimental biogas production system. (Source: Bala and Satter, 1991).

The causal diagram helps in the development of the reference mode [25], supporting the translation of the dynamic behavior of the biogas production process into a graphical form. The dynamic behavior of the variables in the model was referenced against the experimental data to validate the model.

\subsection{Stock Flow Diagramming (SFD) and Model Equation}

The basic building blocks of a feedback loop are the levels and rates. The level variables describe the condition of a system at any time, and the rate variables show how fast the levels are changing. The new value of a level is calculated by adding to or subtracting from the previous value, the change that has occurred during the intervening time interval. An auxiliary is an elaboration of the rate equation. In the stock-flow diagram of the model (Figure 3 - presented under Results and Discussion), there are two level variables, which are represented as hydrolysis-acidogenesis and acetogenesis-methanogenesis. The hydrolysis-acidogenesis level variable is characterized by the hydrolysis rate constant $(\mathrm{k})$, hydrolyzable rate of the substrate $(\alpha)$ and it is expressed by the first-order kinetic model.
The causal diagram helps, first, to describe the concept of the system, which in this case is biogas production from the anaerobic process, and second, to identify the key variables that drive the system in the model. For this study, the process of generating the causal diagram of the anaerobic process led to the identification of all relevant parameters and influential variables used for this study. Figure 1 reflects the reviewed literature [11] on biogas production. This diagram describes the anaerobic digestion process a substrate will normally undergo for the production of biogas, which includes hydrolysis, acidogenesis, acetogenesis, and methanogenesis. The figure could also be used to explain the effect of inhibition that may likely occur during an anaerobic digestion process [26, 27]. 


$$
k=\frac{1}{m \cdot t_{0}} \cdot \exp (m) \cdot(1-m)
$$

For this study, Equation (3)s was modified into a simple form in Equation (5):

$$
G_{t}=A \cdot k
$$

In the hydrolysis stage of an anaerobic digestion process, carbohydrates, fats, and proteins are all broken down into smaller molecules by this initial step of the process [28]. Acidogenic bacteria degrade the products of hydrolysis into volatile fatty acids. Some hydrogen, carbon dioxide, $\left(\mathrm{CO}_{2}\right)$, and acetic acid are also produced, which will skip the acetogenesis stage [29].

In the hydrolysis-acidogenesis stage of biogas production, $\mathrm{CO}_{2}$ and hydrolyzable carbon are produced as indicated in the $\mathrm{SDM} . \mathrm{CO}_{2}$ is characterized by the kinetic average specific rate of digestion (KC1) and carbon dioxide potential of fermentation (AC1), while the hydrolyzable carbon, which is characterized by the hydrolysis rate constant, enters into the acetogenesis-methanogenesis stage.

The acetogenesis-methanogenesis stage is expressed in the SDM as an integral part of the output from hydrolyzable carbon. This stage is where methane and carbon dioxide produced during the anaerobic digestion process are captured. The output methane is characterized by the methane rate constant $(\mathrm{km})$, methane potential (Am), and batch time, while that of carbon dioxide is characterized by the kinetic average specific rate of digestion ( $\mathrm{KC} 1)$, carbon dioxide potential of fermentation ( $\mathrm{AC} 1$ ), and carbon dioxide potential of methanogenesis (AC2). The total gas produced is the sum of the outputs (methane and carbon dioxide).

\section{Results and Discussion}

The objectives of this study are to generate a causal loop and stock-flow diagrams that represent the kinetics of the biogas production system, develop a system dynamic model for the system, validate, and simulate the model. The section describes and discusses the results obtained from the study.

Figure 2 describes the causal loop diagram (CLD) showing the anaerobic digestion process that substrate undergoes for biogas production, as previously indicated. The figure contains 28 information links showing interconnections in a typical anaerobic digestion system. The first 8 links to the substrate are the factors that affect it in regards of biogas production under anaerobic conditions [30]. The substrate links to the hydrolysis stage, which is the breaking down of the substrate into four different components (water, simple sugars, amino acids, and fatty acids) as shown by the information links in the diagram. These information links connect to the acidogenesis stage, which is the second stage where acidogenic bacteria act on the product of the hydrolysis stage and convert them to carbon dioxide, ammonia, and $\mathrm{H}_{2} \mathrm{~S}$ [31] as shown through information links in the diagram. These links connect to the acetogenesis stage where carbon dioxide, ammonia, and $\mathrm{H}_{2} \mathrm{~S}$ are acted upon by the acetogenic bacteria to produce acetic acid, which leads to methanogenesis stage. In the methanogenesis stage, methanogens metabolize the acetic acids into methane, $\mathrm{CO}_{2}$, $\mathrm{H}_{2} \mathrm{~S}$, and other trace gases, which are the last three information links [30]. The description of this process depicts an ideal anaerobic condition without inhibition.

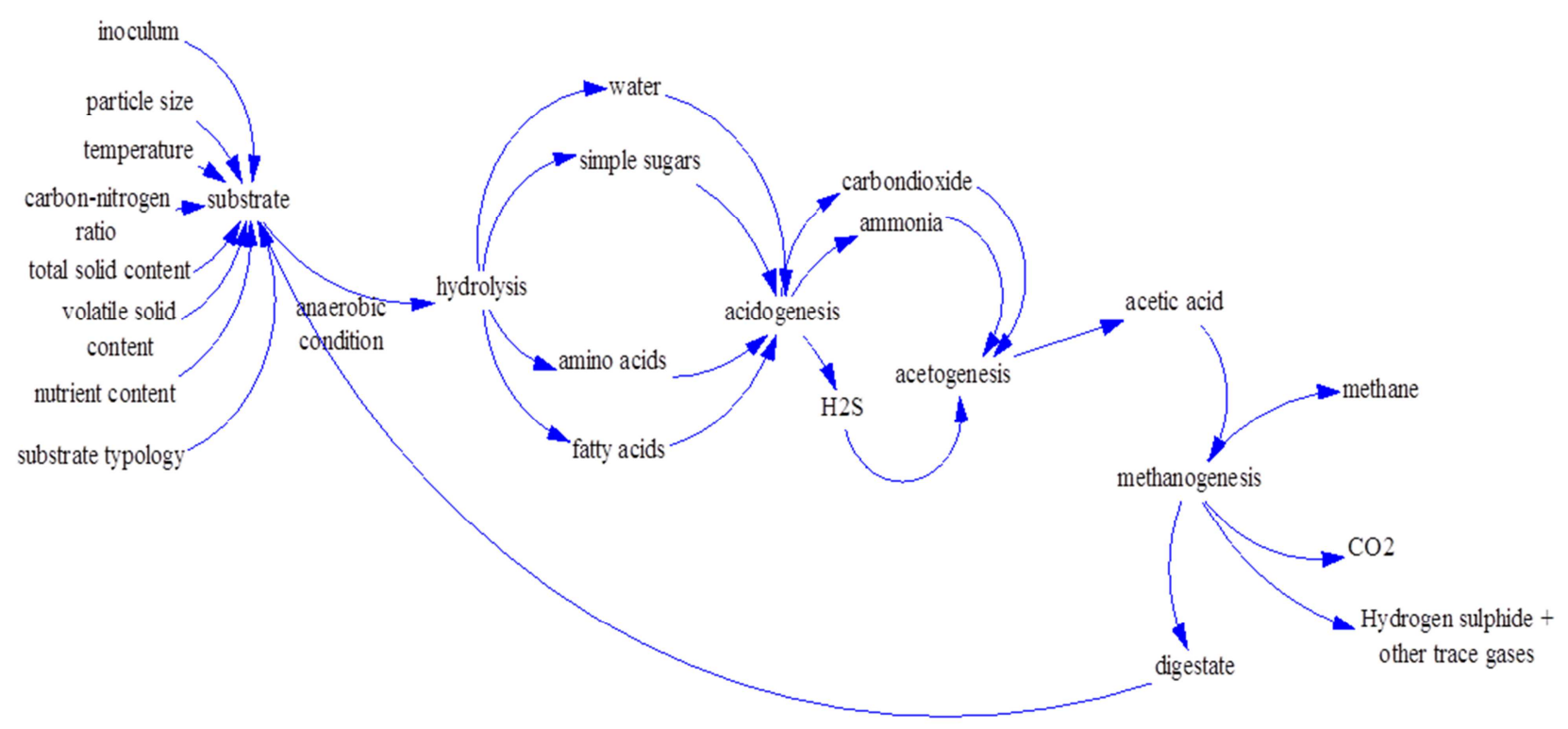

Figure 2. Causal diagram of anaerobic digestion of substrate for biogas production.

Going back to Figure 1 as described earlier, where anaerobic process exhibits two phases namely, "growth" and "death" in the system $[11,32]$. The growth phase indicates a generation of positive feedback, which in the case of biogas production could mean the absence of inhibitors [26] in the biogas production process. The generation of negative feedback or counter-balancing effect implies attaining equilibrium in the system, which in respect to biogas production signifies the death phase where there could be inhibition. The inhibitors are principally ammonia and sulfate/sulphide. During experimental 
research, the condition (pH, non-evacuating the gas) $[33,34]$ in which the digester operated encouraged inhibition. Inhibition could occur in the biodigester for the following reasons: single daily evacuation, substrate exhibiting the presence of ammonia, sulfate, light metals, heavy metals, long-chain fatty acids, organics, and halogenated inorganic compounds in the digester [for example, see 25, 27]. The presence of inhibition affects the production of biogas, leading to low methane yield or instability
[34]. There are two major loops in Figure 1 describing the effect of acid and methane-forming bacteria respectively in the anaerobic digestion process. The two loops in the causal diagram represent the two major phases in the biogas production process namely: hydrolysis-acidogenesis and acetogenesis-methanogenesis. These are distinctly represented as level variables in the System Dynamics model shown in Figure 3.

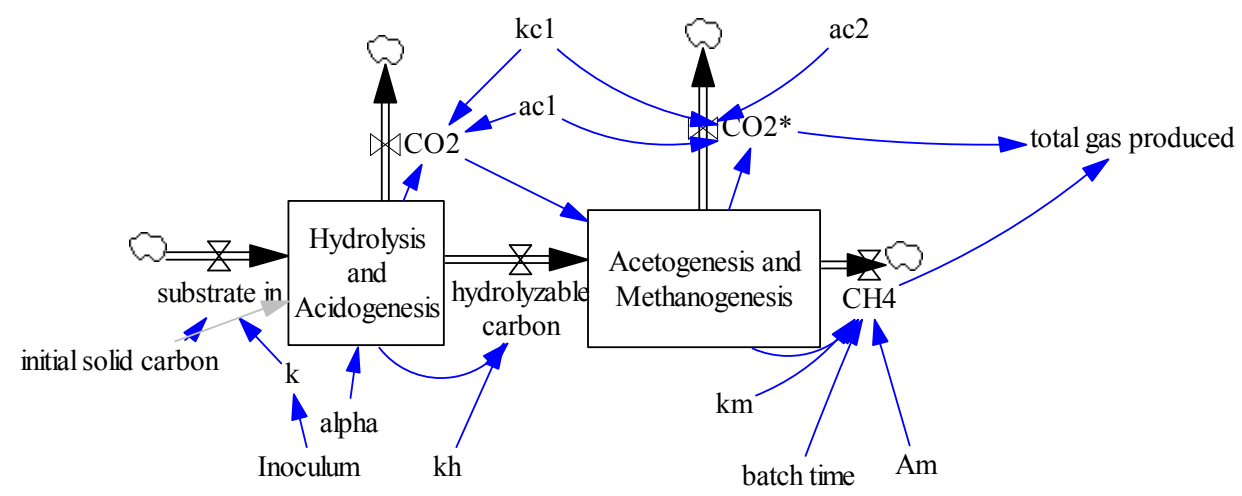

Figure 3. System Dynamic model of a two-stage kinetic model of biogas generation.

\section{Validation and Simulation of the SD model}

The SFD and equations for the kinetics of the biogas production model have been described in the methodology section. This section describes the validation and simulation of the model. As will be seen better in the analysis, the model was validated using laboratory experimental data of biogas production obtained for 30 days retention time. To predict the production of biogas from any substrate, it is necessary to make use of the baseline information, which includes the nutrient content, total and volatile solids (VS) content, chemical and biological oxygen demand, carbon/nitrogen ratio, and presence of inhibitory substances.

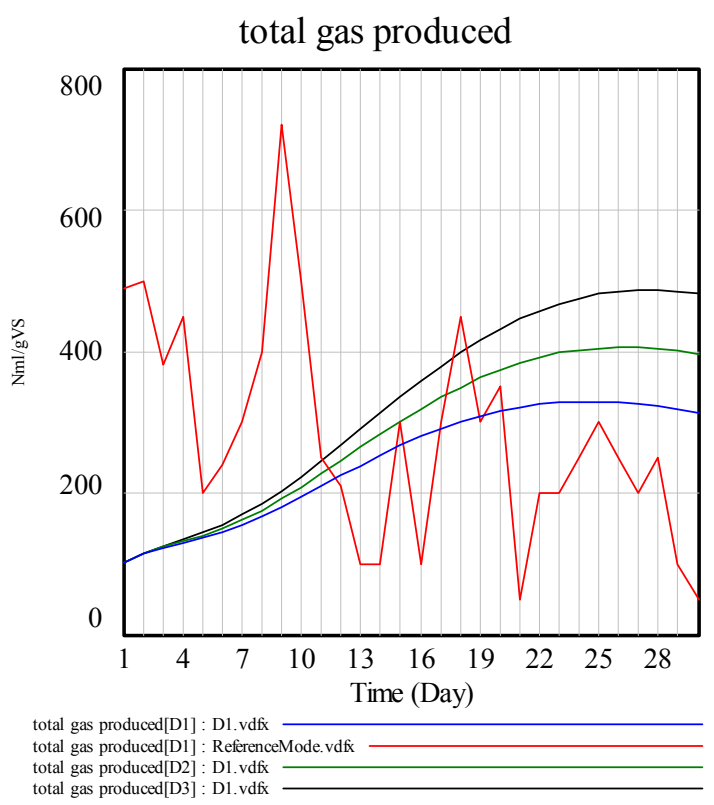

Figure 4. Reference Mode in the Simulations of SDM.

The validation was performed using data obtained from biogas produced from a laboratory experiment. This is the reference Mode in the simulation of the SDM, as shown in Figure 4. From the diagram, it was observed that the predicted modes agree with the experimental, though not perfectly, which is due to the fact of inhibition in the experimental work and other factors.

In the kinetics of hydrolysis-acidogenesis, the first-order kinetic model showed that the solid material (substrate) reduced exponentially with an increase in time, as shown in Figure 5. In figure 6 , it was observed that the consumption of substrate and production of methane and carbon dioxide followed exponential decay and logarithmic growth. In addition, carbon dioxide started early compared to methane and reached a maximum rate after early because of the strong and resilient characteristics of fermentative microorganisms. The biogas production rate in the model rises exponentially with an increase in time, and after reaching the maximum point, it decreases with an increase in time. Also, there was a significant lag phase between methanogenesis and the fermentation stage in the model [35].

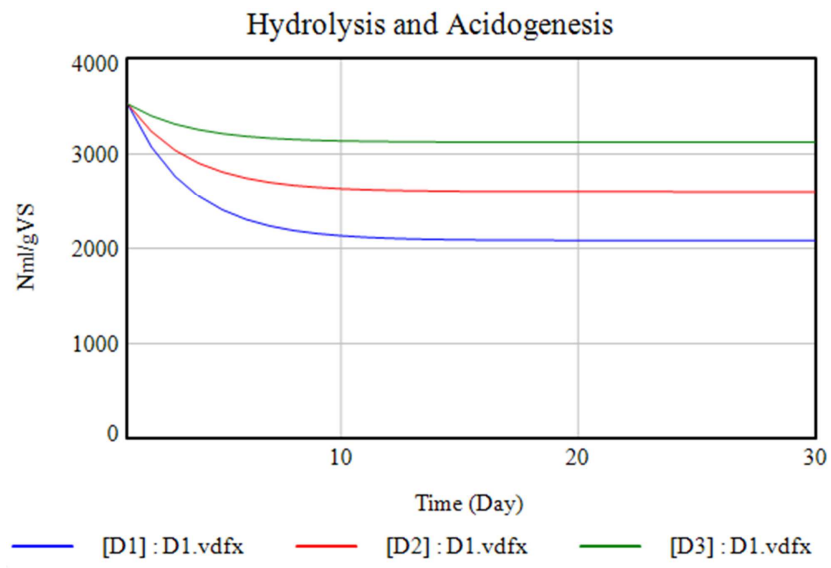

Figure 5. Kinetics of hydrolysis-acidogenesis. 


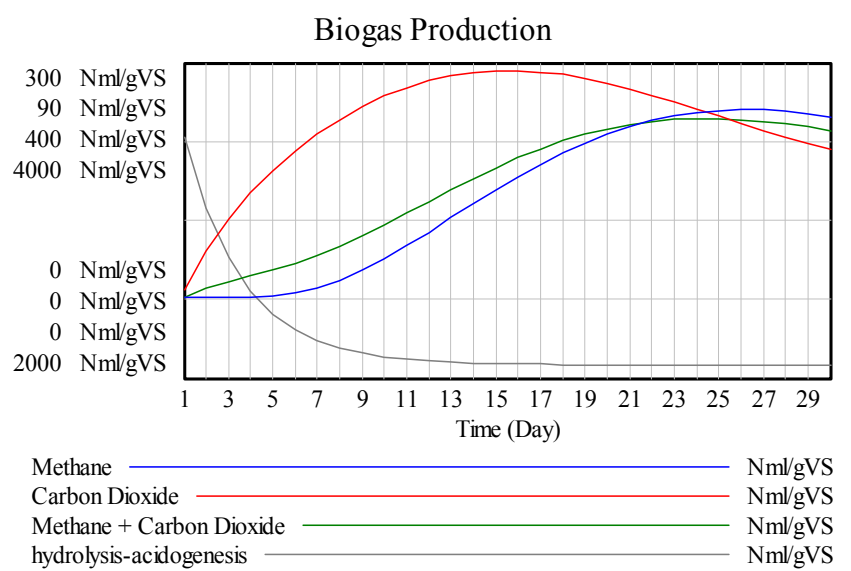

Figure 6. Cumulative Biogas Production.

\section{Conclusion and Recommendations}

In this study, a System Dynamics model of a two-stage kinetic model was established. In developing the SD model, causal and stock flow diagrams were generated to explain the anaerobic digestion process of a vegetal matter. From the simulated results of the SDM, the first-order kinetic model showed that the solid material (substrate) reduced exponentially with an increase in time in the hydrolysis-acidogenesis stage. This is in addition to the fact that the biogas production rate rises exponentially with an increase in time and after reaching the maximum point and decreasing with increasing time. The model results also showed a significant lag phase between methanogenesis and the fermentation stage. This phenomenon is found to link the inoculum to substrate ratio during the digestion process. [36].

Further, inferences were made when the experimental data were compared with the simulated results from the SDM. Biogas production from vegetal matter in the experimental data was found to be almost consistent with that from the SDM simulated result. The variation in the results is attributed to inhibition demonstrated in the experimental work [26, 27]

\section{References}

[1] Lloyd, P. J. (2017). The role of energy in development. Journal of Energy in Southern Africa, 28 (1), 54-62.

[2] Stern, D. I. (2004) Economic Growth and Energy. Encyclopedia of Energy, Volume 2. Pg $35-51$.

[3] Arto, I., Capellán-Pérez, I., Lago, R., Bueno, G., and Bermejo, R., (2016). The energy requirements of a developed world. Energy for Sustainable Development, 33, pp. 1-13.

[4] UNEP (1997) Environment for People: Building Bridges for Sustainable Development, UNEP, New York, pp. 4-9.

[5] Bertram and Doug Clover (2010). Generating Electricity in a Carbon- constrained world.

[6] US EPA (2017) Environmental Economics: Economics of
Biofuels.

[7] Technavio (2015) Five Processes Being Used to Turn Waste into Energy.

[8] Arsova (2010) Anaerobic digestion of food waste.

[9] Weinrich, S., Koch, S., Bonk, F., Popp, D., Benndorf, D., Klamt, S., \& Centler, F. (2019). Augmenting biogas process modeling by resolving intracellular metabolic activity. Frontiers in microbiology, 10.

[10] Hamawand, I., \& Baillie, C. (2015). Anaerobic digestion and biogas potential: simulation of lab and industrial-scale processes. Energies, 8 (1), 454-474.

[11] Bala, B. K. (1991). System dynamics modeling and simulation of biogas production systems. Renewable energy, 1 (5-6), 723-728.

[12] Fang Yulin, Ying Q.; Kai, H. L., Feng B., 2018. System dynamics modeling for information systems research: Theory development and practical applications. MIS Quarterly, Volume 42, No (4), pp. 1303-1329.

[13] Gavala, H. N., Yenal, U., Skiadas, I. V., Westermann, P., Ahring, B. K., 2003. Mesophilic and Thermophilic Anaerobic Digestion of Primary and Secondary Sludge: Effect of Pretreatment at Elevated Temperature. Journal of Water Research, Volume 37, pp. 4561-4572.

[14] Ghatak, M., \& Mahanta, P. (2017). Kinetic model development for biogas production from lignocellulosic biomass. International Journal of Technology, 8 (4), 673-680.

[15] Abdullahi, I., 2011. Effect of Kinetic Parameters on Biogas Production from Local Substrate using a Batch Feeding Digester. European Journal of Scientific Research, Volume 57, pp. 626-634.

[16] Pham Van, D., Hoang, M. G., Pham Phu, S. T., \& Fujiwara, T. (2018). A new kinetic model for biogas production from co-digestion by batch mode. Global Journal of Environmental Science and Management, 4 (3), 251-262.

[17] Deepanraj, B.; Sivasubramanian, V.; Jayaraj, S., (2015). Experimental and kinetic study on anaerobic digestion of food waste: The effect of total solids and $\mathrm{pH}$. J. Renewable Sustainable Energy, 7 (6).

[18] Kythreotou, N.; Florides, G.; Tassou, S. A., (2014). A review of simple to scientific models for anaerobic digestion. Renewable Energy, 71: 701-714.

[19] Nopharatana, A., Pullammanappallil, P. C., Clarke, W. P., 2007. Kinetics and Dynamic Modeling of Batch Anaerobic Digestion of Municipal Solid Waste in a Stirred Reactor. Waste Management, Volume 27, pp. 595-603.

[20] Pham Van, D., Hoang, M. G., Pham Phu, S. T., \& Fujiwara, T. (2018). Kinetics of carbon dioxide, methane, and hydrolysis in the co-digestion of food and vegetable wastes. Global Journal of Environmental Science and Management, 4 (4), 401-412.

[21] Kafle, G. K.; Chen, L., (2016). Comparison on batch anaerobic digestion of five different livestock manures and prediction of biochemical methane potential (BMP) using different statistical models. Waste Manage. (Oxford), 48: 492-502.

[22] Schofield, P.; Pitt, R.; Pell, A., (1994). Kinetics of fiber digestion from in vitro gas production. J. Anim. Sci., 72 (11): 2980-2991. 
[23] Tjørve, K. M., \& Tjørve, E. (2017). The use of Gompertz models in growth analyses, and new Gompertz-model approach: An addition to the Unified-Richards family. PloS one, 12 (6), e0178691.

[24] Rossi, R. M., de Oliveira Grieser, D., de Almeida Conselvan, V., \& Marcato, S. M. (2017). Growth curves in meat-type and laying quail: a Bayesian perspective. Semina: Ciências Agrárias, 38 (4), 2743-2754.

[25] Sterman, J. D. (2000). Business dynamics: systems thinking and modeling for a complex world: Jeffrey J. Shelstad, Indianapolis, IN.

[26] Cornet, C., \& Euverink, G. J. W. (2017). Inhibiting factors in the anaerobic digestion process for biogas production (Doctoral dissertation, Faculty of Science and Engineering).

[27] Chen, Y., Cheng, J. J., \& Creamer, K. S. (2008). Inhibition of anaerobic digestion process: a review. Bioresource Technology, 99 (10), 4044-4064.

[28] Adekunle, K. F., \& Okolie, J. A. (2015). A review of the biochemical process of anaerobic digestion Advances in Bioscience and Biotechnology, 6 (03), 205.

[29] Salomoni, C., Caputo, A., Bonoli, M., Francioso, O., Rodriguez-Estrada, M. T., \& Palenzona, D. (2011). Enhanced methane production in a two-phase anaerobic digestion plant, after $\mathrm{CO}_{2}$ capture and addition to organic wastes. Bioresource Technology, 102 (11), 6443-6448.

[30] Stan, C., Collaguazo, G., Streche, C., Apostol, T., \& Cocarta, D.
(2018). Pilot-scale anaerobic co-digestion of the OFMSW: Improving biogas production and startup. Sustainability, 10 (6), 1939.

[31] Bougrier, C., Delgenes, J. P., \& Carrere, H. (2007). Impacts of thermal pre-treatments on the semi-continuous anaerobic digestion of waste activated sludge. Biochemical Engineering Journal, 34 (1), 20-27.

[32] Mauerhofer, L. M., Pappenreiter, P., Paulik, C., Seifert, A. H., Bernacchi, S., \& Simon, K. M. R. (2019). Methods for quantification of growth and productivity in anaerobic microbiology and biotechnology. Folia microbiologica, 64 (3), 321-360.

[33] Obiukwu, O. O., \& Nwafor, M. O. (2016). Comparative evaluation of batch and continuous process biogas production from animal wastes. International Journal of Ambient Energy, 37 (1), 29-35.

[34] Okorigwe, E. C., \& Agbo, S. N. (2007). Gas evacuation effect on the quantity of gas production in a biogas digester. Trends Appl. Sci. Res, 2 (3), 246-250

[35] Boulanger, A., Pinet, E., Bouix, M., Bouchez, T., \& Mansour, A. A. (2012). Effect of inoculum to substrate ratio (I/S) on municipal solid waste anaerobic degradation kinetics and potential. Waste Management, 32 (12), 2258-2265.

[36] Ali Shah, F., Mahmood, Q., Maroof Shah, M., Pervez, A., and Ahmad Asad, S. (2014). Microbial ecology of anaerobic digesters: the key players of anaerobiosis. The Scientific World Journal, 2014. 